\title{
BREACHING OF SEA DIKES
}

\author{
Laurits Bernitt ${ }^{1}$ and Patrick Lynett ${ }^{2}$
}

\begin{abstract}
Risk Analysis of sea dikes is a fundamental tool for protection of human health and safety, private and public property and cultural heritage. The modern risk concept defines risk as the product of inundation probability times the consequences of inundation. The risk concept is a versatile tool for any matter, public, private or environmental endangered by storm surges. The hydraulic task in a sea dike risk analysis is the determination of the internal water level. The present breaching intensity model, is part of a connected complex of models for transforming an external surge to an internal inundation. The complex is calibrated on the New Orleans East Back Levee breaches blown by hurricane Katrina in 2005.
\end{abstract}

Keywords: Sea dike, levee, storm surge, overtopping, hydraulic load, back slope strength, grass, hydraulic fill, breach development, breach intensity, length effect, hurricane Katrina, New Orleans, inundation, risk analysis, reliability analysis.

\section{INTRODUCTION}

Sea dikes are lengthy structures that have to sustain high water and wave load. The vast majority of sea dikes are earth structures typically protected by a grass cover, clay layers and occasionally various types of front slope protection. The structure has been applied for thousands of years in various designs, and numerous problems and failures have been experienced. Basically the dike may fail because of overflow, overtopping, piping, seepage, geotechnical instability or wave erosion. However, wave overtopping should constitute the most important failure mode, or the ultimate limit stage, for a well designed sea dike. For reason of limited resources one cannot build indefinitely high, and one day any back slope will face an excessive overtopping rate. The excessive overtopping gives rise to local erosion in the back slope and the on-set of a migrating head cut; Rijkswaterstaat et al. 2008. When the head cut starts lowering the free-board of the sea dike, the overtopping becomes even larger and an incipient breach is in development.

Overtopping from short crested wind waves gives rise to a highly stochastic loading of the back slope. The ability of the turf and the earth materials to resist this forcing is defined as the strength of the back slope. Owing to the nature of turf, soil structure, geotechnical properties, worms, rodents, contractor skill, maintenance etc. the back slope strength is stochastic, also. The formation of incipient breaches is thus a question of stochastic load exceeding stochastic strength and must be of a completely stochastic nature.

When the incipient breach has been blown the inundation of the hinterland relies on the temporal development of the breach. Even a minor breach of a major sea dike will involve large quantities of material. Consequently an increasingly deterministic development should be expected in homogeneous structures, as opposed to the stochastic generation process. The present paper assumes a stochastic generation of breaches and a deterministic development according to Bernitt and Madsen (2008).

With the advent of Hurricane Katrina on 29 August 2005, the levees around New Orleans broke massively, as the result of an excessive load, IPET 2006. Both back slope and front slope erosion took place. Owing to the investigation work of IPET, some of the most well documented dike failure data have been made public, IPET 2007-09. Additionally, by courtesy of USACE and IPET the most recent simulation of water level and wave conditions at New Orleans East Back Levee during Hurricane Katrina has been supplied. By an analysis of these data, a calibrated temporal breach development model and a calibrated breach intensity function for grass covered back slopes, has been derived.

\section{DEFINITIONS, PARAMETERS, OCCURRENCE AND DEVELOPMENT OF BACK SLOPE BREACHES}

\section{Strength and Load Parameters}

With the numerous overtopping experiments conducted in recent years, see Figure 1, it has become increasingly well documented that the critical loading of a well designed sea dike, is a hydraulic erosive loading from overtopping waves; Rijkswaterstaat et al. 2008. Because of its convenient quantification

\footnotetext{
${ }_{1}^{1}$ M.Sc., Manager, IC Bernitt, www.ICBernitt.com, Teglgaardsvej 14B, DK-7620 Lemvig, Denmark, ICBernitt@mail.dk

2 Ass. Professor \& Director, Haynes Coastal Engineering Laboratory, Department of Civil Engineering, Texas A\&M University, College Station, USA
} 
during laboratory experiments, the average overtopping rate per unit length, $\mathrm{Q}_{\mathrm{o}}$, has been used to characterize the hydraulic load. It has been clearly documented by the overtopping experiments in the field, that it is the largest of the waves that does the majority of the erosive work. However, in a depth limited coastal environment the extreme and the average overtopping rates are related to one another, and consequently the average overtopping rate constitutes a convenient relative measure of the forcing.

An increasing database of critical overtopping rates, $Q_{v d M}$, for various back slopes and structures is being developed worldwide by the three overtopping simulators presently in operation. The overtopping experiment conducted March 2010 at the Vechtdijk in the Netherlands, revealed that the critical average overtopping rate of a grass covered sand dike back slope inclined 1:4 would be somewhere in the interval $30-50[1 / \mathrm{s} / \mathrm{m}]$.

Thus both load $\mathrm{Q}_{\mathrm{ot}}$ and strength $\mathrm{Q}_{\mathrm{vd} M}$ of dike back slopes may be expressed in terms of average overtopping rates. However stable these parameters might appear, it should be kept in mind that both load and strength are of a highly stochastic nature.

The force/strength analogy is very popular for description of failures. However an average overtopping rate is not a forcing, but a facilitator of a stochastic flow impact. The actual forcing is expected to be proportional to the square of the velocity at the impact area. For the moment being these details of the erosion process have not been revealed and quantified.

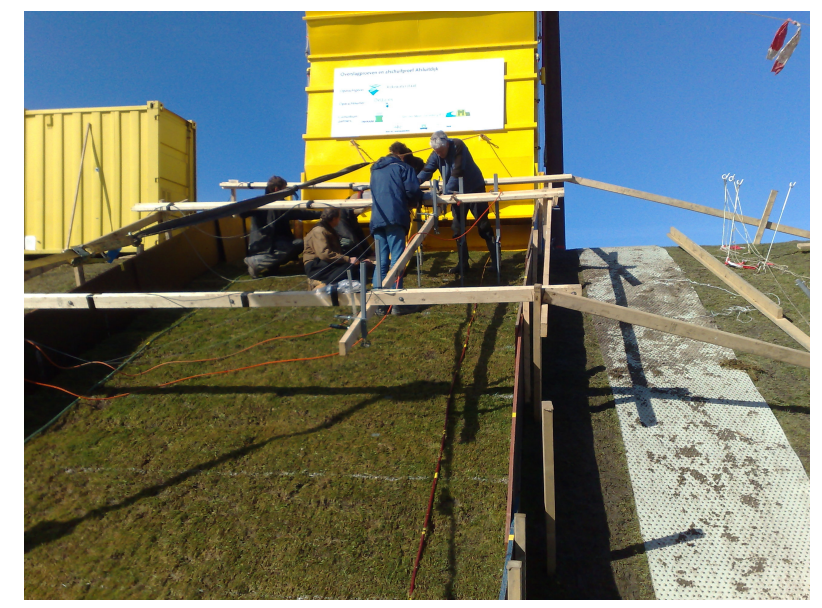

Figure 1. The overtopping simulator on the Afsluitdijk, 11 March 2009 The Netherlands. Preparation and instrumentation of the back slope for wave loading.

\section{The Length Effect}

In the past sea dikes have been designed irrespective of their length. However, it is recognized that the length must affect the probability of a breach, e.g. Vrouwenvelder and Steenbergen 2003.

In the present context the length effect is defined as the dependence between the length of a sea dike and the probability of a breach. The longer a uniform dikeline under uniform load the more likely the occurrence of a breach. By uniform load is understood an identical hydraulic climate in terms of water level and sea state all along the dikeline and thus producing the same average overtopping.

\section{Breach Intensity Model}

Breaching of sea dikes may be perceived as the exhaustion of stochastic strength by stochastic load. The longer the dikeline under hydraulic load the larger the probability, that a weak spot is exposed to an excessive hydraulic load. This dependence may be expressed as the intensity of breaches as a function of excessive loading:

$$
\mathrm{DB}\left(\mathrm{Q}_{\mathrm{ot}}\right)=\mathrm{B} /\left(\mathrm{Q}_{\mathrm{ot}}{ }^{2}-\mathrm{Q}_{\mathrm{vdM}}{ }^{2}\right)
$$

Where DB denotes distance per breach, the inverse of the intensity, $\mathrm{Q}_{\mathrm{tot}}$ denotes the actual peak average overtopping experienced, $B$ is a characteristic constant, and $Q_{\mathrm{vdM}}$ denotes the strength limit of the back slope. 
To conform to the load/strength forcing analogy, the square of the overtopping rates in relation (1) have been assumed to express the excessive loading more adequately. Relation (1) should be perceived as the central or average outcome of numerous storm surge/structure interactions to allow for the stochasticness of the generating process.

\section{Temporal Breach Development Model}

By surveys of the New Orleans breaches, IPET 2006, and Danish breaches, Bernitt and WL Delft 2008, it has been documented that the typical sea dike breach will develop horizontally above a characteristic threshold level F. Based on the $3^{\text {rd }}$ December 1999 breach at Brøns, Denmark, Bernitt and Madsen 2008 have established the following model for the temporal development of the crest to crest width $\mathrm{B}(\mathrm{t})$ in the supercritical stage of flow,

$$
\mathrm{dB}(\mathrm{t}) / \mathrm{dt}=\mathrm{K}(\mathrm{g}(\eta-\mathrm{F}))^{1 / 2}
$$

where $\mathrm{t}$ denotes time, $\mathrm{K}$ denotes a characteristic degradation constant, $\mathrm{g}$ denotes gravity and $\eta$ denotes the external water level.

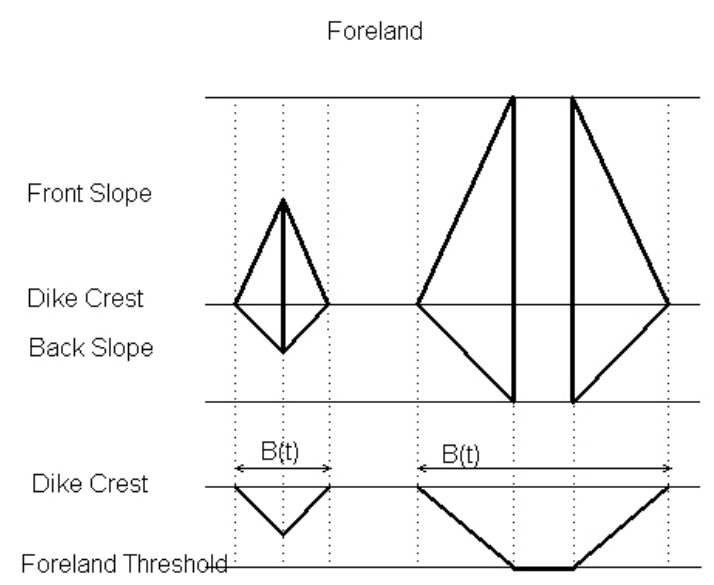

Figure 2. Principal plane and horizontal view of the incipient and the mature breach of a dikeline, Bernitt and Madsen 2008.

The definition of width is illustrated in Figure 2. Equation 2 is of a deterministic nature owing to the large volumes of material eroded as the breach is expanding in a typical sea dike constructed from local fairly homogeneous materials.

\section{HURRICANE KATRINA AND THE NEW ORLEANS EAST BACK LEVEE}

Hurricane Katrina in lake Borgne 29 August 2005

Hurricane Katrina made landfall at Buras, south of New Orleans on 29 of August 2005 and subsequently passed east of the city generating enormous devastation, IPET 2007-09. The course of the centre depression track is indicated in Figure 3. 


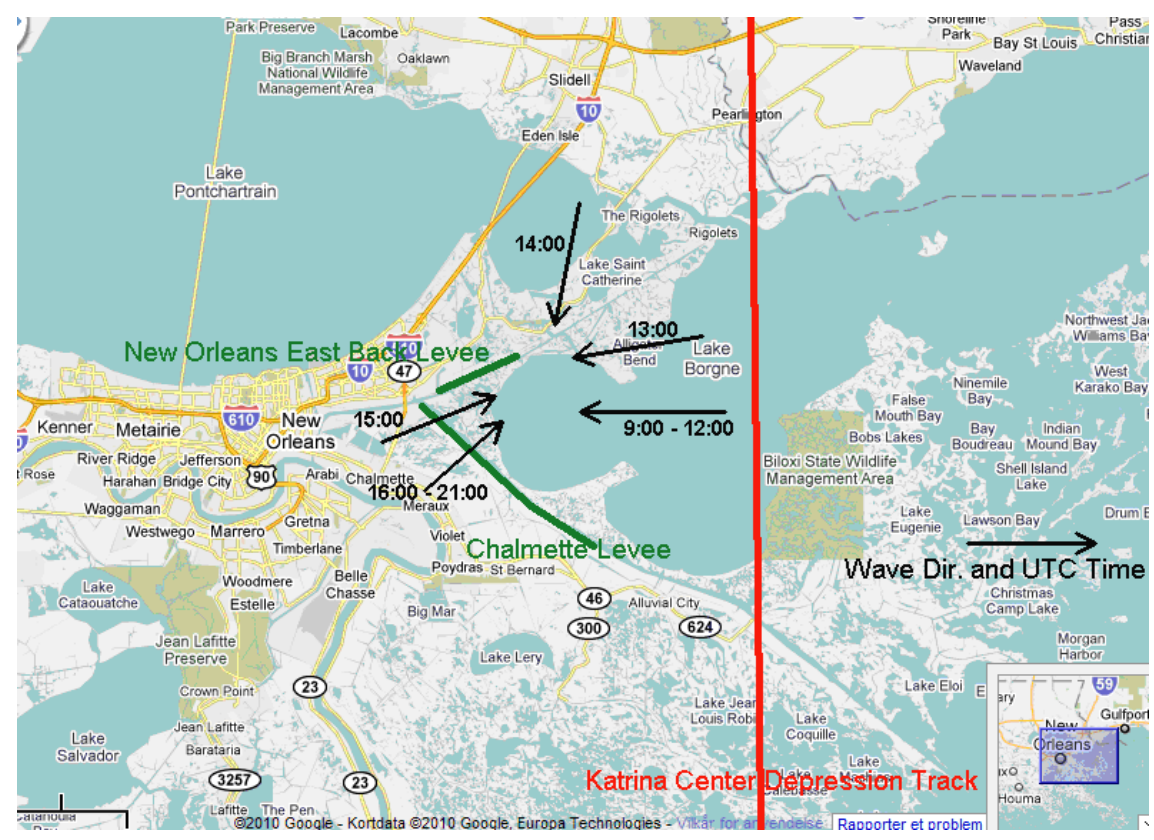

Figure 3. Katrina center depression track on 29 August 2005 and main wave directions in lake Borgne during the high flood stage, wave data by courtesy of IPET and USACE.

During the passage of hurricane Katrina, a $225^{\circ}$ shift of the wave fields in lake Borgne was simulated during just 2 hours owing to the proximity to the depression center.

Two of the most devastated dikelines are facing lake Borgne, the Chalmette Levee to the West and the New Orleans East Back Levee (NOEBL) to the Northwest. From the post disaster aerials of the dikelines, IPET 2006, there is no obvious evidence of front slope erosion on NOEBL as opposed to the Chalmette Levee. This is in good agreement with the absence of direct wave impact to NOEBL, as seen from Figure 3. Consequently there is good reason to assume that the NOEBL breaches derived from back slope failures.

\section{New Orleans East Back Levee, devastation and load, 29 August 2005}

An aerial and a cross-section from the devastated NOEBL after hurricane Katrina is displayed in Figure 4. From the Figure are identified a number of breaches with a remarkably uniform threshold level around $+71 \mathbf{1}^{\prime}$ NAVD 88 . The crest to crest distance, the width of the breaches, is clearly recognized. Another feature from all the NOEBL aerials in the IPET (2006) reporting is the apparent lack of incipient damages. Apparently the back slopes are either intact or breached. Only a very few incipient back slope breaches, are discernible.

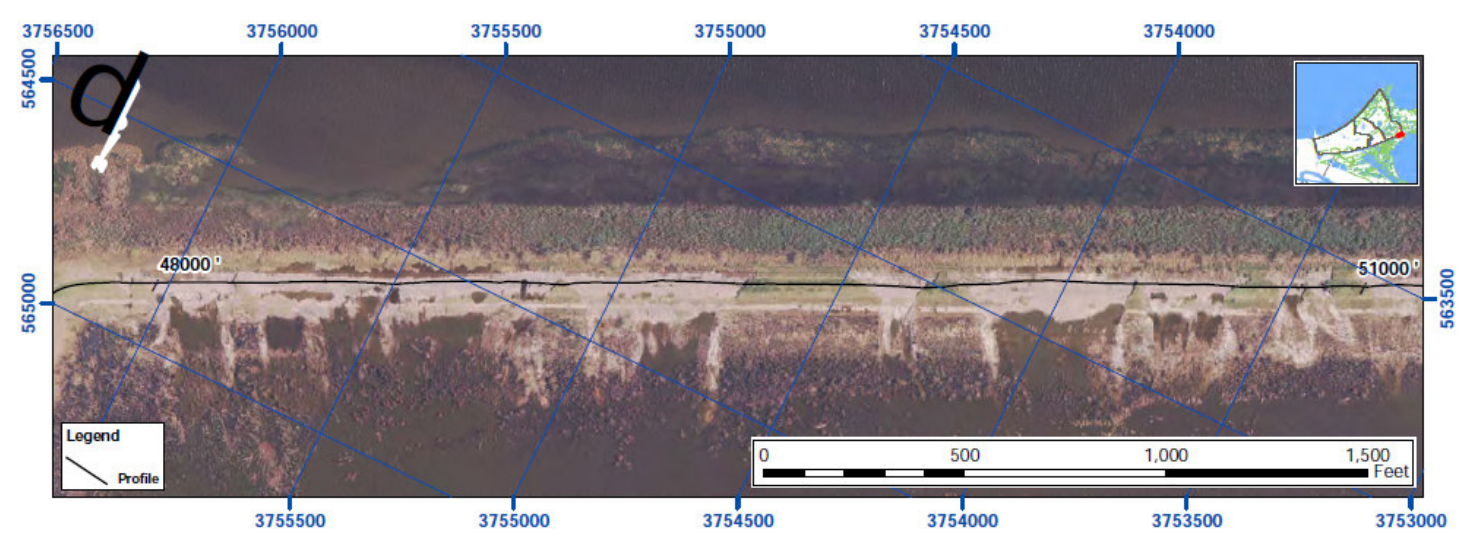




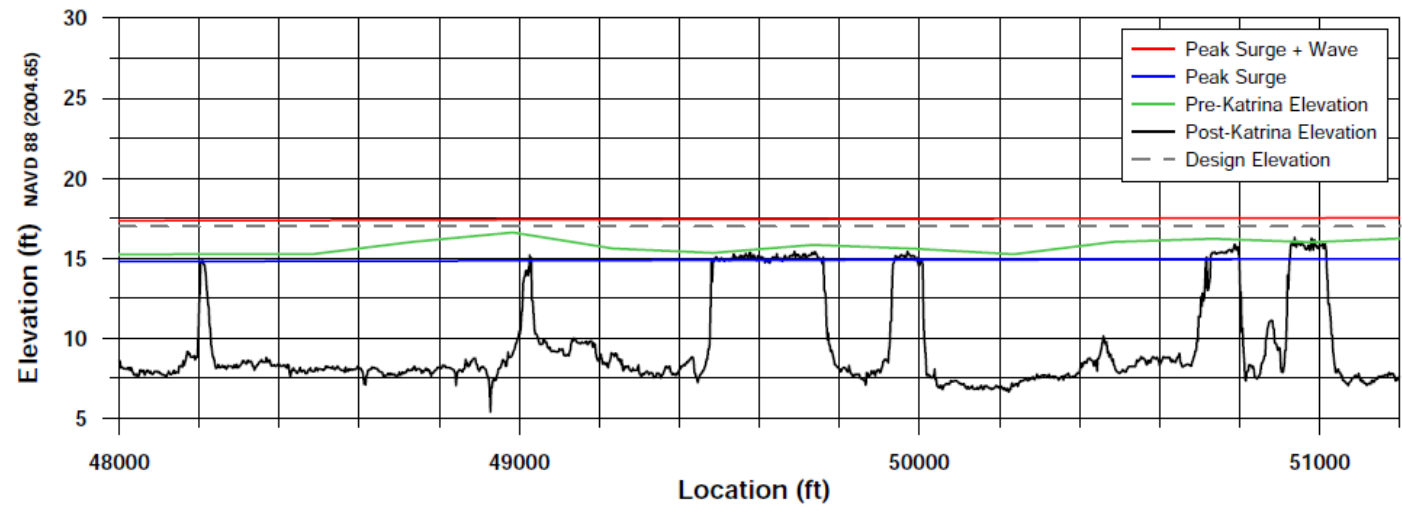

Figure 4. Aerial (opposite side) and cross-section along the crest of NOEBL from station 48000 to 51000 , IPET 2006.

By courtesy of IPET/USACE the most recent time series of simulated water level and wave conditions in the middle of the Golf Intracoastal Water Way (GIWW) at the SE bend of NOEBL has been obtained. Based on this time series the wave conditions at the foot of NOEBL and the overtopping has been calculated, see Figure 5. Both a classical overtopping calculation according to Van der Meer and Janssen 1994 and according to Boussinesq modeling is supplied. Only the eastern wavefield, prior to the passage of the depression centre, gave rise to excessive overtopping in the $59 \mathrm{l} / \mathrm{s} / \mathrm{m}$ range.

NOEBL were exposed to various rates of overtopping for 10 hours, which is an exceptional duration. The overtopping peak occurring between 11:00 and 13:00 hours UTC is of a more usual storm load appearance. When the surge culminated at 17:00 UTC a new local wave field of smaller waves, with smaller periods, had build up from SW.

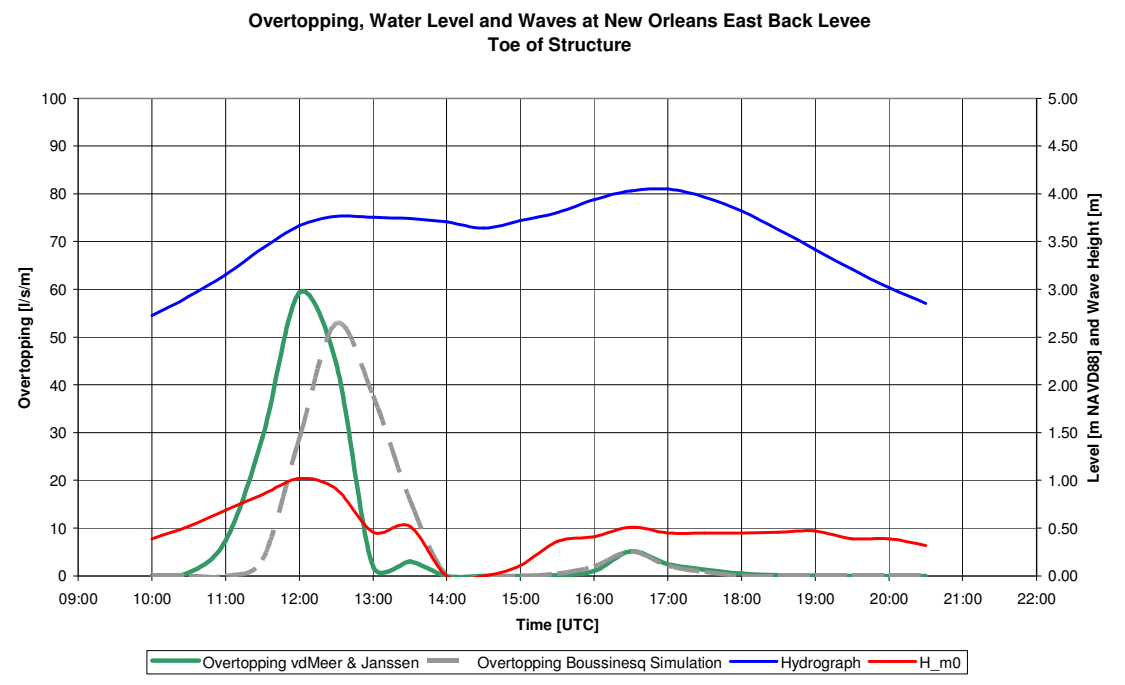

Figure 5. Hydraulic loading of the NOEBL during Hurricane Katrina; overtopping, surge height, and significant wave height.

\section{Analysis of the NOEBL Archetype Breach}

From the IPET 2006 reporting, 26 breaches can be counted along the GIWW from the SE bend and to pump station 15 , that is station 47,750 to 60,500 . The breaches vary from $9 \mathrm{~m}$ to $622 \mathrm{~m}$ in length, and the entire population, distributed into $10 \mathrm{~m}$ classes, is displayed in Figure 6. This distribution is apparent, because some of the breaches have most likely merged with one another. 


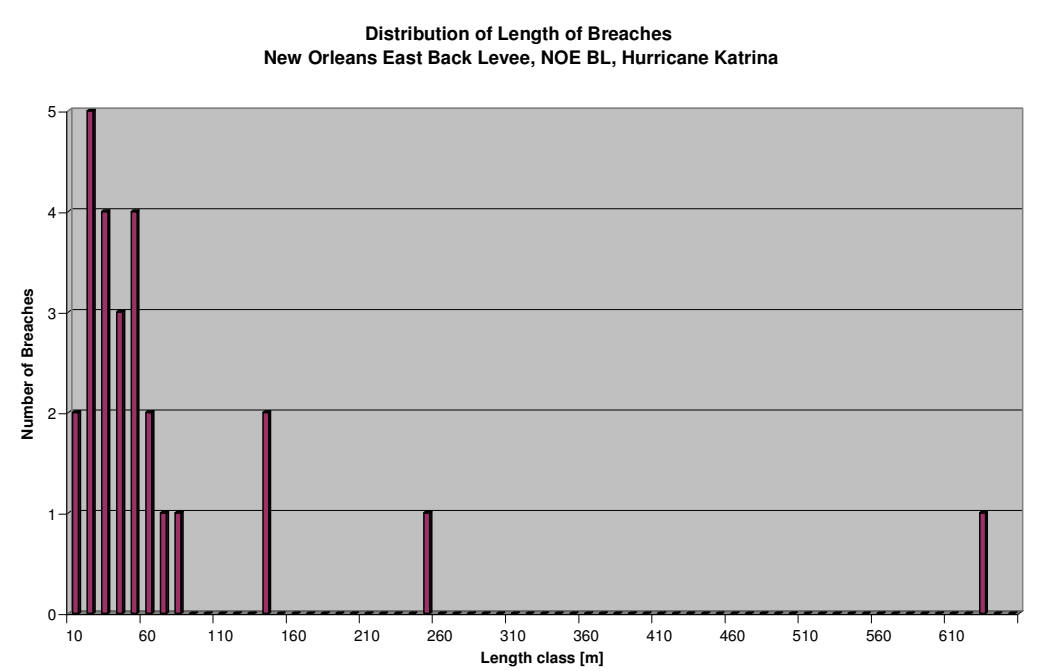

Figure 6. Apparent distribution of length of breaches between st. 47,750 to 60,500 NOEBL after hurricane Katrina.

Among the breaches in Figure 6 there must be a group of archetype breaches. The archetype breach is defined as a breach blown at the peak of the overtopping load and developing according to equation (2) until the water level falls below the hydraulic threshold.

In Bernitt and Madsen 2008 the degradation constant of the Rejsby sea dike, with an erodable cross-section of $89 \mathrm{~m}^{2}$, has been calculated to 0.000434 . The core of the sea dike consisted of $40 \%$ silt and sandy silt and $60 \%$ sand. The NOEBL dike core consisted of hydraulic fill, and the erodable crosssection above the threshold at $+712^{\prime}$ NAVD 88 , measured $281 / 2 \mathrm{~m}^{2}$. Consequently the degradation constant of the NOEBL may be estimated to 0.00136. If this degradation constant is applied in equation (2) and it is assumed that the breach was blown at the peak of the average overtopping rate, the archetype breach may be estimated to either $143 \mathrm{~m}$ or $135 \mathrm{~m}$, depending on which kind of overtopping calculation is applied. In fact the statistics in Figure 6 contains a group of two $135 \mathrm{~m}$ breaches. These breaches are thus assumed to constitute the archetype breach; a singular breach that is blown at the peak of the overtopping load and developing until the surge fall below the hydraulic threshold.

The two archetype breaches are shown in greater detail in Figure 7. Two characteristic fans of erosive products are extending from each of the erosive fronts and into the hinterland. On the inside of each breach, large scour ponds have developed. By calibrating the breach model (2) on these breaches the degradation constant ends at $\mathrm{K}_{\mathrm{NOEBL}}=0.00128$.

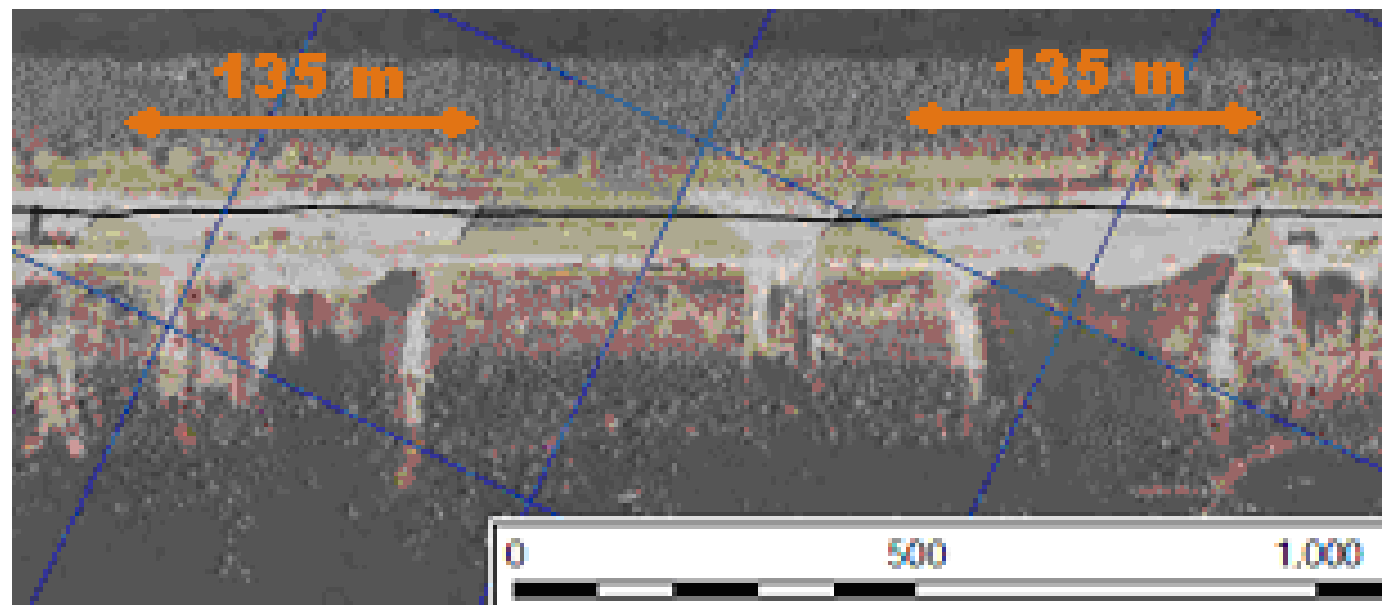

Figure 7. The two archetype breaches on NOEBL with characteristic fans of erosive products and scour ponds in the hinterland, IPET (2006). 
If the longer breaches are perceived as mergers of archetype breaches, one may estimate the total number of archetype breaches. The $244 \mathrm{~m}$ breach, Figure 6, may be composed by 2 archetype breaches, while the extremely long $622 \mathrm{~m}$ breach may be composed by at least 5 archetype breaches. In total it is thus estimated that at least 9 archetype breaches were blown at the peak of the storm.

It is important to note that the archetype breaches are localized on the easternmost $1615 \mathrm{~m}$ of NOEBL. In total $1136 \mathrm{~m}$ or $70 \%$ of this reach disappeared during hurricane Katrina, which underline the extreme impact to NOEBL. The width of the foreland and the vegetation may have mitigated the wave impact to the remaining section of NOEBL, where no large archetype breaches are found.

The temporal development of the archetype breach, the flow rate and the accumulated volume of inundation is depicted in Figure 8. The inflow peaked at $230 \mathrm{~m}^{3} / \mathrm{s}$, and the total volume of inflow, the inundation, accumulated to $3.4 \mathrm{Mm}^{3}$. Taking into consideration that at least 9 archetype breaches were in joint operation on this reach, the extreme devastation by hurricane Katrina is emphasized.

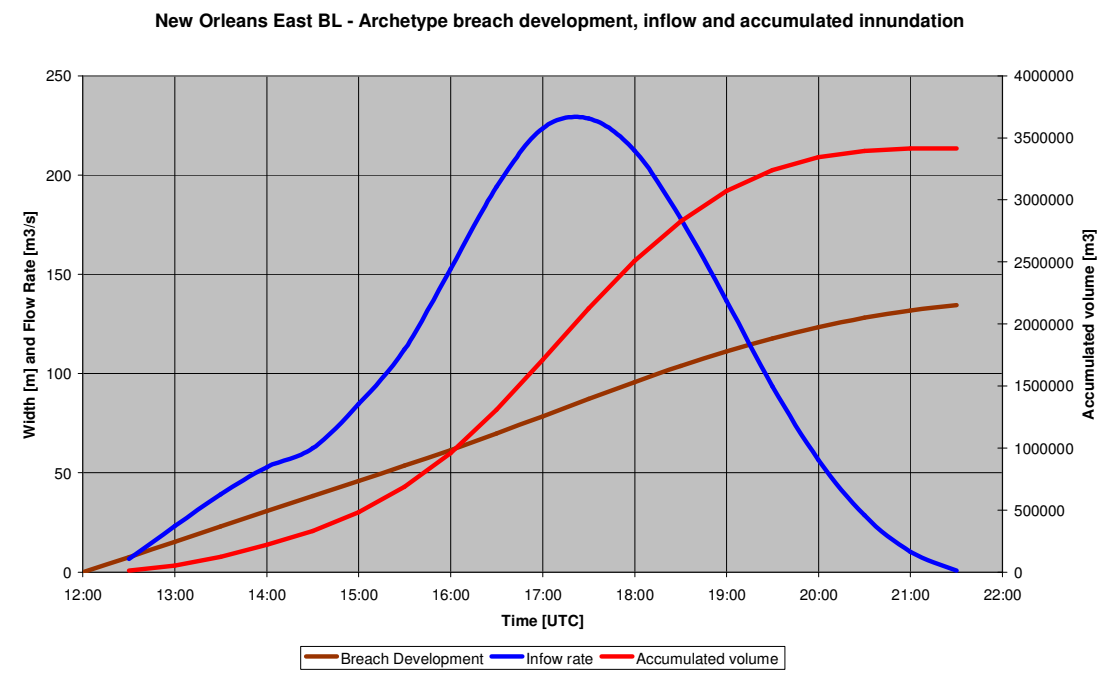

Figure 8. The $135 \mathrm{~m}$ final length archetype breach of NOEBL, inflow and accumulated volume of inundation generated by hurricane Katrina.

\section{Occurrence of Breaches NOEBL}

By resolving the 2 largest breaches, see Figure 6, into at least 7 archetype breaches, the total population of breaches on NOEBL during hurricane Katrina is increased to at least 31 . With the calibrated temporal breach development model (2) in hand, one may estimate the time of occurrence of each individual breach. The estimated times of occurrence of the individual breaches on NOEBL during hurricane Katrina, are presented in Figure 9.

The massive generation of archetype breaches took place around 12:00 hours UTC and lead to an accumulated breach length of $1136 \mathrm{~m}$. However, the numerous minor breaches occurring from 16:00 hours and on, had a combined length of $726 \mathrm{~m}$ and constituted an important devastation, also. The smallest breach of just $9 \mathrm{~m}$, comprising approximately $160 \mathrm{~m}^{3}$ of material, is estimated to have opened just $1 \frac{1 / 2}{2}$ hour before the surge took off.

The most likely explanation to the occurrence of the minor breaches is a combination of complete infiltration and some overtopping. NOEBL is under hydraulic load for nearly 7 hours after the primary hydraulic loading 11:00 to 13:00 has taken place. This long duration allowed the structure to get completely soaked. All the damages blown during the primary loading constituted weak spots and most likely made the core material, hydraulic fill, openly exposed and finally washed out as numerous minor breaches. This interpretation is confirmed by the absence of numerous incipient back slope damages. Owing to the extreme duration of the short periodic wave impact from SW, front slope failure, see Bernitt 2005, cannot be ruled out completely, though the front slope appeared free of incipient damages, also. 


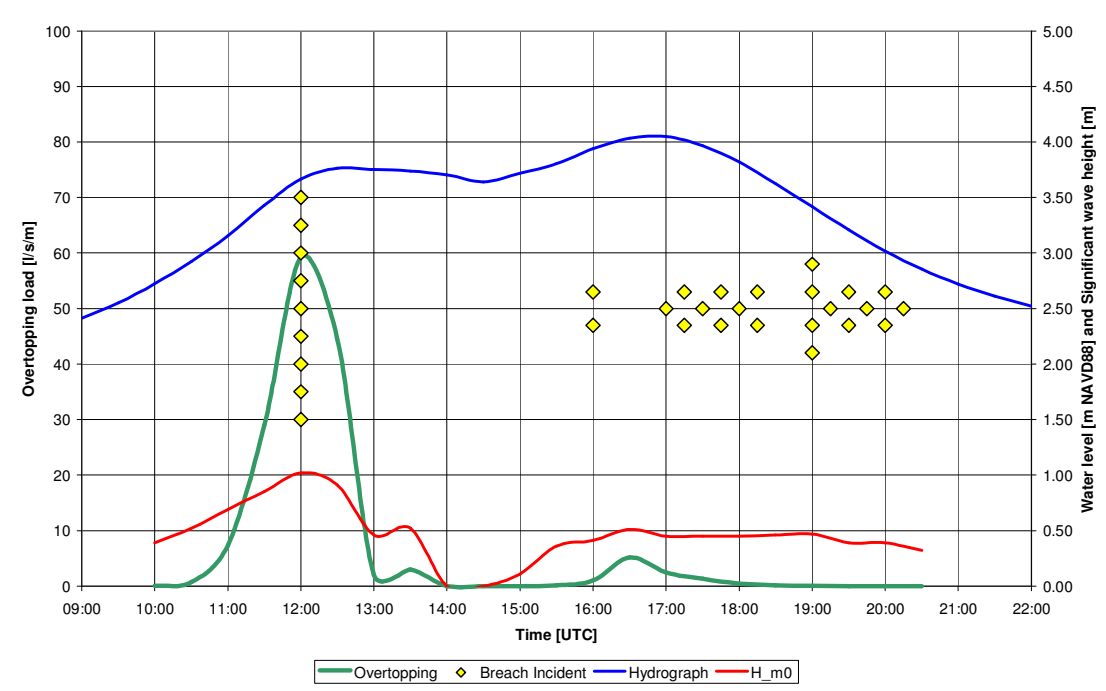

Figure 9. Estimated time of occurrence of archetype and minor breaches on NOEBL during hurricane Katrina 29 August 2005. The advent of each breach is indicated by a yellow square on the context of the hydraulic load.

\section{CALIBRATION OF THE BACK SLOPE BREACH INTENSITY FUNCTION}

\section{Basic Breach Intensity Information}

Owing to the devastation and trauma incurred by sea dike disasters, it is very rare that thorough hydraulic/structural information like the IPET reporting from NOEBL is available.

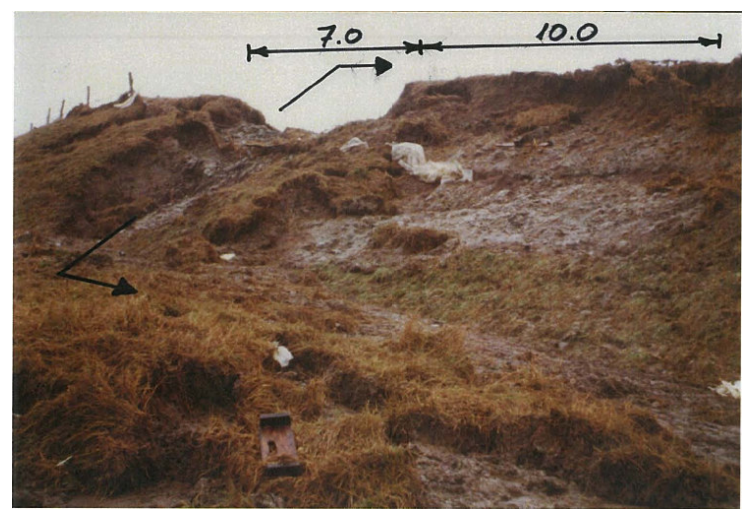

Figure 10. Back Slope Damage at station 4,3, Rejsby Sea Dike, 3 January 1976, Denmark, Bernitt 2005.

From the above analysis of the breaches incurred by hurricane Katrina on NOEBL it is estimated that an overtopping load of $59[1 / \mathrm{s} / \mathrm{m}]$ lead to at least 9 archetype breaches on a particular reach length of $1615 \mathrm{~m}$. That is a breaching intensity of $180 \mathrm{~m} / \mathrm{breach}$. The reach was destructed by $70 \%$.

In Bernitt 2005 a reporting from the 1976 surge on the Rejsby dikeline, Denmark, may be found. At the southern $2100 \mathrm{~m}$ of this dikeline, 12 back slope damages were found. One of these damages lowered the crest level by $1.1 \mathrm{~m}$, see Figure 10, though the dikeline did not breach. The loading was estimated to $35[1 / \mathrm{s} / \mathrm{m}]$; Bernitt 2005.

Both structures had a grass covered back slope protecting a rather sandy core material. NOEBL had a back slope inclination 1:3 while the Rejsby Sea Dike had a substantially steeper inclination of 1:1.5 back in 1976. The structures also deviate with respect to crest width, but the scarcity of information does not allow to discern between these parameters. 
Calibration of the Back Slope Breach Intensity Function for Grass Covered Sandy Sea Dikes

In spite of the scarcity of information the NOEBL 2005 and Rejsby 1976 cases provide the necessary minimum to calibrate equation (1). The calibration is depicted in Figure 11, and the calibrated constants $B$ and $Q_{v d M}$ are listed in equation (3). The Van der Meer strength limit, $Q_{v d M}$, ends at $32[1 / \mathrm{s} / \mathrm{m}]$, which is within the limits discovered during the Vechte overtopping tests conducted in March 2010. The constant B ends at $0.44\left[\mathrm{~m}^{5} / \mathrm{s}^{2}\right]$. The length effect is clearly recognized by the curvature of the breach intensity function in Figure 11.

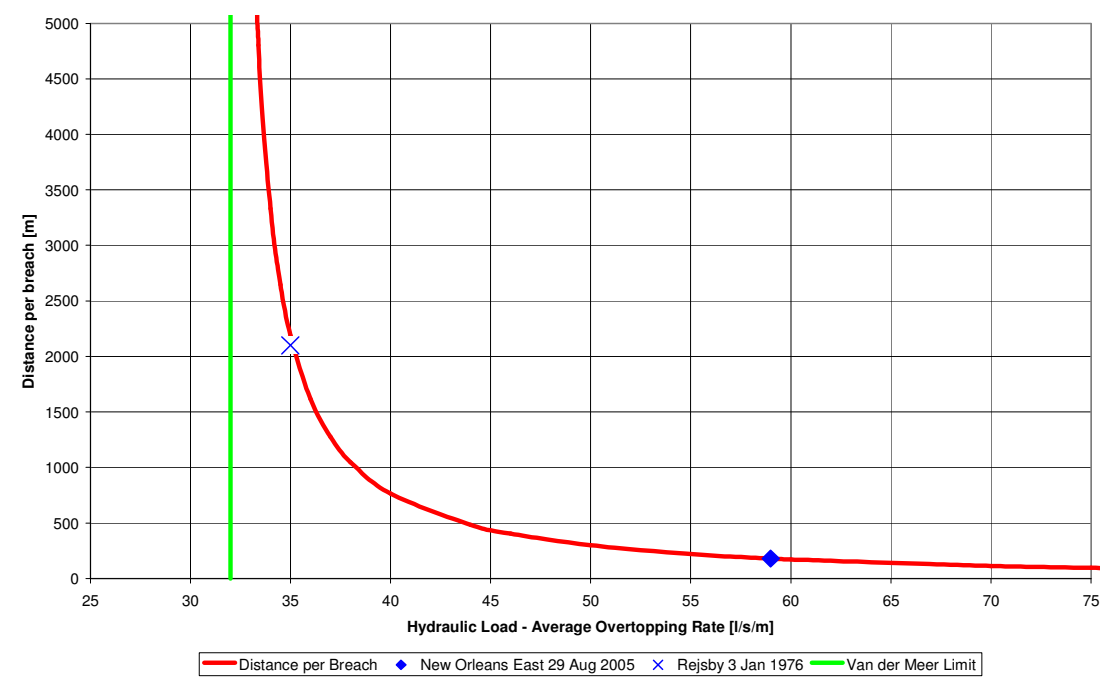

Figure 11. Calibration of the back slope breach intensity function for grass covered sea dikes with a sandy core.

$$
\mathrm{DB}\left(\mathrm{Q}_{\mathrm{ot}}\right)=440,000\left[1^{2} / \mathrm{s}^{2} / \mathrm{m}\right] /\left(\mathrm{Q}_{\mathrm{ot}}^{2}-(32[1 / \mathrm{s} / \mathrm{m}])^{2}\right)
$$

\section{CONCLUSION AND DISCUSSION}

A new model for description of breaching of grass covered sea dike back slopes from excessive wave overtopping has been formulated. The model consists of a stochastic breach intensity function (1) and a deterministic temporal breach development model (2). Load and strength are described in terms of average overtopping rates. The breach intensity function represents the average outcome of numerous storm surge/structure interactions. The breach intensity function includes the length effect.

The models have been calibrated on the numerous breaches at New Orleans East Back Levee, NOEBL, generated during hurricane Katrina, IPET 2008. Hurricane Katrina represents one of the most destructive storm surges ever reported, with up to $70 \%$ degradation of a particular NOEBL reach.

Two $135 \mathrm{~m}$ long archetype breaches of NOEBL have been identified and used for calibration of the temporal breach development model. The breach intensity function for a grass covered sea dike with a sandy core has been calibrated on the NOEBL 2005 and Rejsby 1976 cases and a pronounced length effect is visible from the calibration. Both the breach intensity function and the temporal breach development model are remarkably simple and operational, and greatly facilitate risk and reliability analysis of sea dikes.

The breach intensity function (1) relies on the load/strength analogy. Basically it is assumed that the intensity of breaches is proportional to the excessive loading of the dikeline. At the present level of understanding, load and strength parameters are expressed in relative terms as overtopping rates. Important structural parameters like crest height, crest width, core material, cover layers, back slope inclination, and surface structure and reinforcement are incorporated into the critical overtopping rate $\mathrm{Q}_{\mathrm{vdM}}$. The load parameter $\mathrm{Q}_{\mathrm{ot}}$ is a relative measure of the stochastic forcing. At the present level of research and understanding it is difficult to formulate and calibrate a more general breach intensity function and in dimensionless terms. 
In the long term it is anticipated that the strength parameter may be characterized by a critical flow velocity. At that moment, the flow and the load generated by the flow on the back slope will be greatly emphasized.

Owing to the scarcity of data, only a minimum calibration of a basic back slope breach intensity function, Figure 11, has been completed. With more breach cases available, a better calibration diversified by structural strength and hydraulic load parameters may be obtained. With more data available, a standard deviation may be derived, and the central risk assessment may then be extended by a reliability assessment.

Cooperation on processing and exploitation of the numerous dike disasters experienced worldwide could turn these traumatic events into simple and operational risk and reliability models, safeguarding the future.

\section{ACKNOWLEDGEMENTS}

USACE by its Coastal and Hydraulics Laboratory and IPET are greatly acknowledged for supplying their latest simulation data from hurricane Katrina. Van der Meer Consulting B.V. is cordially thanked for its hospitality and open discussions of overtopping simulator experiments and results.

\section{REFERENCES}

Bernitt, L.M. (2005). Risikoanalyse af digebeskyttede områder (In Danish), Danish Coastal Authority, Lemvig, December 2005.

Bernitt, L.M. and WL Delft. (2008). Risk Analysis of Dike Protected Areas, rough translation of Risikoanalyse af digebeskyttede områder, WL Delft and Danish Coastal Authority, Lemvig, May 2008.

Bernitt, L.M. and Madsen, H.T. (2008). Temporal Development of a Sea Dike Breach, Proceedings of $31^{\text {th }}$ International Conference on Coastal Engineering, ICCE 2008, Hamburg, ASCE, 3237-3249.

IPET - Interagency Performance Evaluation Task Force. (2006). Performance Evaluation of the New Orleans and Southeast Louisiana Hurricane Protection System, Volume V - The Performance Levees and Floodwalls, Appendix 18 Erosion of New Orleans and St. Bernard Levees, Attachment A - New Orleans East Back Levee, Attachment B - Chalmette Levee, US Army Corps of Engineers, 1. June 2006, Final Draft.

IPET - Interagency Performance Evaluation Task Force. 2007-2009. Performance Evaluation of the New Orleans and Southeast Louisiana Hurricane Protection System, Final Reports, Volume I to IIIV, US Army Corps of Engineers.

Rijkswaterstaat, ComCoast and Zeeweringen. (2008). Erosion strength of inner slopes of dikes against wave overtopping. Preliminary conclusion after two years of testing with the Wave Overtopping Simulator, Deltares, Van der Meer Consulting B.V., Royal Haskoning, Alterra and Infram, Versie 1.1, August 2008.

Van der Meer, J. W. and Janssen, J.P.F.M. (1994). Wave Run-up and Wave Overtopping at Dikes and Revetments, Delft Hydraulics, August 1994.

Vrouwenvelder, A. C. W. M. and Steenbergen, H. M. G. M. (2003). Theoriehandleiding PC-ring, Deel B: Statistische modellen, TNO Bouw, 2003-CI-R0021, DG Rijkswaterstaat, April 2003. 